Dossiê: Segurança pública e reforma das polícias na América Latina

\title{
Desafios da reforma das polícias no Brasil Permanência autoritária e perspectivas de mudança
}

\author{
Challenges of police reform in Brazil \\ Authoritarian permanence and perspectives of change \\ Rodrigo Ghiringhelli de Azevedo*
Andréa Ana do Nascimento**
}

Resumo: O artigo debate os desafios para a reforma das Polícias no Brasil, trazendo um breve histórico das origens das forças policiais no Brasil e do legado autoritário sobre suas estruturas institucionais. Em seguida, são apresentadas e discutidas as tentativas de reforma nas polícias do estado do Rio de Janeiro, com enfoque especialmente na implantação das Unidades de Polícia Pacificadora (UPPs) e das Delegacias Legais (PDL). A partir destas experiências concretas de reforma, são apresentadas e discutidas as propostas de reforma legal inseridas na PEC 51, assim como no relatório da Comissão Nacional da Verdade, que sugeriu uma série de reformas das estruturas policiais no Brasil.

Palavras-chave: Reforma das polícias. Unidades de polícia pacificadora. Delegacias legais. PEC 51.

\begin{abstract}
The article discusses the challenges to reform the Police in Brazil, based on a brief historical review of the origins of the police force in Brazil and the authoritarian legacy of its institutional structures. Then we present and discuss attempts to reform the police of the state of Rio de Janeiro, focusing especially on the implementation of the Pacifying Police Units (UPPs) and Legal Police Stations (PDL). From these concrete reform experiments are presented and discussed proposals for legal reform entered into the PEC 51, as well as the National Truth Commission report, which suggested a number of reforms of the police structures in Brazil.
\end{abstract}

Keywords: Reform of police. Pacifying police units. Legal police stations. PEC 51.

*Doutor em Sociologia pela Universidade Federal do Rio Grande do Sul (Ufrgs, Porto Alegre, Brasil), professor na Pontifícia Universidade Católica do Rio Grande do Sul (Pucrs) em Porto Alegre, RS, Brasil, onde atua nos PPG em Ciências Sociais e em Ciências Criminais, integrante do Instituto de Ciência e Tecnologia do Instituto de Estudos Comparados em Administração Institucional de Conflitos (INCT-Ineac) e do Fórum Brasileiro de Segurança Pública <rodrigo. azevedo@pucrs.br>.

**Doutora em Sociologia pela UFRJ, Rio de Janeiro, Brasil. Bolsista de pós-doutorado (PNPDCapes) no PPG em Ciências Sociais da Pucrs, Porto Alegre, Brasil<andrea77ana@gmail.com>.

Civitas, Porto Alegre, v. 16 , n. 4, p. 653-674, out.-dez. 2016

Exceto onde especificado diferentemente, a matéria publicada neste periódico

é licenciada sob forma de uma licença

Creative Commons Attribution-NonCommercial-NoDerivatives 4.0 International License 


\section{Introdução}

Há quase três décadas vivemos sob a égide de uma Constituição democrática. Entretanto, as relações entre as polícias e os cidadãos no Brasil ainda se caracterizam em muitos contextos pela desconfiança, pelo abuso de poder e pela falta de critérios para o uso da força, produzindo altas taxas de letalidade e de vitimização policial. A transição democrática garantiu os direitos políticos e o processo eleitoral, mas não assegurou os direitos civis a todos os cidadãos e a reforma das instituições policiais. O controle legal da violência permaneceu abaixo de um nível aceitável e os principais obstáculos não foram enfrentados. Persistem graves violações de direitos humanos, resultado de uma "violência endêmica, radicada nas estruturas sociais, enraizada nos costumes, manifesta quer no comportamento de grupos da sociedade civil, quer no dos agentes incumbidos de preservar a ordem pública" (Zaluar, 2007, p. 65-66).

Imersas em uma cultura que combina o uso excessivo da força contra determinados grupos sociais e uma lógica de funcionamento burocrática e bacharelesca no âmbito da investigação criminal, a volta à democracia não alterou as estruturas da polícia, tradicionalmente comprometidas com a proteção das elites e do estado e a supressão dos conflitos sociais. Essa tradição se faz presente em diversos países da América Latina, nos quais o controle da violência é utilizado como forma de manter a ordem social, justamente por nunca ter se efetivado a universalização dos direitos de cidadania (Pinheiro, 1997).

A situação da segurança pública no Brasil é tão dramática, que ninguém está satisfeito: nem a sociedade, nem os policiais. 60 mil pessoas são assassinadas por ano no país, em uma taxa que se aproxima dos 30 por 100 mil habitantes ao ano. ${ }^{1}$ A maioria das vítimas são jovens pobres e negros, moradores de territórios socialmente vulneráveis. As investigações não esclarecem em média mais do que $8 \%$ desses crimes. Ainda assim, temos a quarta população carcerária do mundo e a taxa de crescimento mais elevada do encarceramento (Brasil, 2015). As prisões são territórios à margem da lei, superlotadas e dominadas por facções criminais, que nelas arregimentam novos adeptos, impondo aos presos um pesado excedente de pena.

São muitas as críticas ao modelo policial e à arquitetura institucional da segurança pública. A União historicamente participa pouco, salvo nas crises,

\footnotetext{
${ }^{1}$ Dados do 9o Anuário do Fórum Brasileiro de Segurança Pública, 2015. <forumseguranca. org.br/produtos/anuario-brasileiro-de-seguranca-publica/9o-anuario-brasileiro-de-segurancapublica>.
} 
embora a partir do final dos anos 90, com a criação da Senasp (Secretaria Nacional de Segurança Pública), tenha havido maior preocupação do governo federal com a indução de políticas nos estados, com repasse de recursos e iniciativas importantes na área de formação, além da criação da Força Nacional de Segurança Pública e do sistema federal de presídios (Azevedo, Cifali, 2016). Os municípios não tem atribuições relevantes na área da segurança pública, de acordo com o artigo 144 da Constituição, e somente começaram a ter participação na prevenção ao crime, em alguns casos específicos, a partir do Pronasci (Programa Nacional de Segurança com Cidadania) (Azevedo, 2012).

O peso maior recai sobre os estados, e as estruturas policiais estaduais, embora similares na divisão em duas metades, têm histórias e culturas institucionais que guardam especificidades importantes, assim como homologias significativas.

Diante de tantas insuficiências e crises, a experiência internacional, as boas práticas nacionais e o bom senso indicam que as mudanças são urgentes, necessárias e viáveis, estimulando a cooperação e a integração entre os diversos entes federativos, instituições de justiça e segurança e da própria sociedade civil, para estender ao campo da segurança pública a transição democrática. O objetivo deste artigo é fazer uma reflexão sobre as experiências e propostas de reforma das polícias no Brasil. Partimos de uma breve contextualização da história das polícias, seguida de uma discussão mais prática sobre as tentativas de reforma e sobre as propostas que estão na arena de debates. Para isso elencamos as experiências do Rio de Janeiro, cujos dados apresentados são um desdobramento da tese de doutoramento Quando um homem da lei torna-se um sem lei: os caminhos da corrupção policial (Nascimento, 2014). A metodologia utilizada foi qualitativa com utilização de observação direta e entrevistas nas instituições envolvidas, além da revisão bibliográfica de outros estudos relacionados ao tema e análise documental.

\section{Histórico, estrutura e práticas policiais}

No Brasil as polícias estaduais encontram-se divididas em duas instituições: a polícia militar com atribuições relacionadas ao policiamento ostensivo e atividades preventivas e repressivas de combate ao crime, e a polícia civil, com status de polícia judiciária, cujo papel é investigar crimes.

Segundo Holloway (1997), o papel das polícias no período colonial era o de controlar as classes populares e os escravos. A polícia agia de forma arbitrária, impondo os costumes estabelecidos por uma sociedade patriarcal e aristocrática. Com a passagem para o período republicano, o estado do Rio de Janeiro tornou-se a capital federal, e a polícia militar fortaleceu seu papel de 
defesa da ordem pública. A polícia civil continuou atuando como uma polícia judiciária, tendo seu corpo policial ampliado no período republicano.

As instituições policiais brasileiras nasceram separadas, reproduzindo o modelo ibérico, e assim permaneceram, criando identidades distintas e muitas vezes conflitantes. A polícia militar permaneceu com seu papel preventivo/ repressivo vinculado a uma lógica militar de combate ao crime, e exercendo o papel de força auxiliar do exército. E a polícia civil se construiu pautada num modelo burocrático inquisitorial (Lima, 2014).

No interior de cada uma das polícias, com poucas variações de um estado para o outro, também existem divisões ocupacionais bem marcantes. A polícia militar se divide em dois grupos: as praças e os oficiais. Os praças são as patentes com hierarquia mais baixa: soldados, cabos e sargentos, em geral formados por profissionais que possuem nível médio de instrução. Já os oficiais, integrados pelas patentes de tenente, capitão, major, tenente-coronel e coronel, ingressam numa carreira separada e o seu curso de formação é equivalente a uma graduação de nível superior. Sendo assim, um policial da patente mais baixa, ainda que tenha muita expertise profissional, não poderá ascender aos postos mais elevados da polícia militar, a não ser que concorra para a carreira de oficialato.

Na polícia civil, ainda que não haja a militarização, a divisão de carreiras também é bem nítida. Existe a carreira dos policiais que atuam como investigadores, inspetores, comissários e escrivães, cujo nível de formação é o ensino médio. E existe a carreira de delegado, para a qual se exige o bacharelado em direito. Da mesma forma que na polícia militar, essa divisão de carreiras impede que um investigador, por mais qualificado que seja, ascenda a posição de delegado.

Essas divisões bem demarcadas de carreira se evidenciam nos cursos de formação policial. A estrutura e os locais de formação para praças e oficiais e para agentes e delegados da polícia civil são muito distintas. Estudos como o de Caruso (2004) e Nascimento (2008) se dedicaram a apontar essas diferenças no que se refere ao tempo, qualidade e conteúdo desses cursos de formação. Em geral, os estudos apontam que muitas vezes os cursos de formação exercem um papel mais formal do que efetivo para a orientação das práticas policiais, cuja atividade profissional em si é aprendida no dia a dia do trabalho e no contato com os policiais mais experientes.

Esse aprendizado que ocorre no dia a dia do trabalho policial configura-se numa cultura muito própria e numa forma de agir peculiar dos membros dessas instituições. É a chamada cultura policial ou "ethos policial" (Poncioni, 2014; Lima, 2014). Como as policias estaduais têm uma separação institucional 
muito bem demarcada, a cultura policial também opera desta maneira. Em outras palavras, a polícia militar e a polícia civil possuem tradições e aspectos culturais distintos que têm dificultado o trabalho conjunto destas instituições. Muitas vezes, no lugar de atuarem de forma complementar e cooperativa, essas policias acabam atuando de forma concorrente, cada qual tentando tomar as atribuições da outra.

É prática comum que as polícias militares tenham um setor de investigação interna que serviria como fiscalizador da conduta de seus servidores. Todavia, é frequente o desvio dos policiais desse setor para investigação de atividades criminosas como o tráfico de drogas, capturando uma função da polícia civil. Por outro lado, algumas polícias civis criaram grupos tático-operacionais para fazerem operações repressivas de combate ao tráfico em comunidades pobres. É o caso da Coordenadoria de Recursos Especiais (Core) no estado do Rio de Janeiro, que atua na intervenção policial em áreas consideradas de risco, porém esse tipo de atuação costuma ser atribuição da polícia militar. Esses exemplos, demonstram que há uma concorrência nas atribuições das polícias estaduais brasileiras que acaba gerando disputas de competência, status e prerrogativas. $\mathrm{O}$ desafio brasileiro consiste em articular mecanismos que coloquem essas instituições como parceiras e que integrem suas atividades no lugar de promover a concorrência entre elas.

As polícias brasileiras vêm ao longo de sua história, enfrentando dificuldades para atuar na assistência aos cidadãos e na prevenção e esclarecimento de crimes de forma eficiente e transparente. A dificuldade se atualiza na passagem de um contexto político repressivo-ditatorial para um contexto democrático. Durante um importante período da história do Brasil, as polícias foram utilizadas como instrumento de controle político. Elas atuaram de forma violenta e arbitrária contra os opositores dos governos militares, e esse período marcou essas instituições como violadoras dos direitos humanos, legitimadas pelo medo do comunismo e de suas ações terroristas (Torelly, 2012). No que se refere à criminalidade, o desafio está em controlar as taxas criminais que vêm crescendo a cada dia. Segundo o Fórum Brasileiro de Segurança Pública (2015), a letalidade das ações policiais que matam uma pessoa a cada 3 horas no país, e em criar ferramentas mais eficientes de controle e investigação de crimes, cujas taxas de esclarecimento são muito baixas.

O debate sobre a modernização das instituições policiais foi adiado por um longo período, mas já a partir da década de 90 , com o incremento da criminalidade, o tema entrou em pauta, com questões relacionadas à letalidade policial, à formação policial, à ineficiência da investigação criminal, à falta 
de controle institucional e à desmilitarização das polícias sendo amplamente debatidas por diversos atores sociais e institucionais.

Como lembra Roberto Kant de Lima (2014), ao que tudo indica, a organização judiciária colonial portuguesa representou a matriz da nossa organização burocrática estatal, e a burocracia brasileira, incluindo as organizações policiais, reproduziu a seu modo essa matriz inspiradora. Baseada em uma estratégia inquisitorial, de suspeição sistemática, assegurava um estado de fragilização permanente entre os quadros da burocracia e estimulava a formação de lealdades pessoais verticais para a neutralização de tais ameaças potenciais de punição, assim como formas oficiosas invisíveis para reagir a esse controle draconiano e abstrato. Conforme Lima,

Para agravar os efeitos não desejados desse sistema abstrato de fiscalização e controle vigente na burocracia brasileira, seu reflexo nas instituições policiais - responsáveis pelos primeiros procedimentos de investigação e controle de atos supostamente ilícitos, cometidos pelos cidadãos, aí incluídos os agentes do Estado - consiste em que as mesmas têm sua organização e estrutura funcional, na prática, hierarquizadas de maneira excludente, de tal forma que a mera diferença de funções vai-se rebatendo em uma desigualdade de posições. Na Polícia Militar, por um lado, temos duas entradas na profissão, que correspondem a formações e funções diferenciadas, uma para oficiais, outra para praças, sendo que estes dificilmente chegam aos postos mais altos do oficialato; na Polícia Judiciária, temos várias carreiras, mas a principal distinção, de ordem salarial, se verifica entre os delegados - que, embora servidores do Executivo, clamam ver sua carreira incluída entre as chamadas carreiras jurídicas próprias dos operadores do Poder Judiciário, seja na magistratura, seja nas diversas posições institucionais assumidas pelas partes nos processos - e a tiragem, quer dizer, entre as autoridades policiais e os demais agentes policiais. Essas segmentações são acompanhadas de atribuições de autoridade e de regimes disciplinares diferenciados, o que provoca hiatos de comunicação profissional entre os segmentos das corporações, com prejuízo para todos. O sistema de culpabilização revela-se, assim, extremamente perverso, pois usa dois pesos e duas medidas com operadores que estão encarregados de funções no mínimo complementares e, em muitos casos concretos, suplementares e/ou equivalentes. Assim, a desigualdade decorre da posição do sujeito na hierarquia da carreira e não em razão da responsabilidade pessoal decorrente da função. É claro que tal situação funcional vivida internamente na instituição não estimula a produção de normas e protocolos destinados a regular, na prática, as atividades dos agentes; não favorece também a aprendizagem e a prática de formas de tratamento universal e uniforme do público 
a ser atendido pela instituição. Embora a prescrição de tratamento universal e uniforme tanto entre os agentes quanto entre estes e o público, mesmo quando inscrito em leis fundamentais substantivas e processuais, não constitua uma garantia de sua execução na prática, ela pode ser considerada essencial para a normalização da formação dos agentes do Estado democrático e como elemento crucial para uma eventual mudança de paradigma (Lima, 2013, p. 562-563).

Por outro lado, o sistema judicial desvaloriza significativamente a atividade da polícia judiciária, ao situá-la em plano inferior na hierarquia judiciária. A polícia reage a essa posição de subalternidade, uma vez que lhe cabe de fato a tarefa de selecionar os casos que serão investigados e encaminhados ao sistema judicial. Desempenhando este papel, as práticas policiais discricionárias permitem ao sistema judicial supostamente se eximir de quaisquer responsabilidades por práticas discriminatórias e injustas na aplicação da lei, e fazem com que a polícia transforme o seu estigma em identidade, projetando os mecanismos de estigmatização sobre a população que está submetida à sua vigilância. Tudo isso produz o fenômeno identificado por Sapori como a frouxa articulação entre a estrutura formal de uma organização e suas atividades práticas: a organização garante legitimidade na medida em que se conforma cerimonialmente aos mitos institucionais, especialmente através da adequação de sua estrutura. Na execução de suas atividades, entretanto, "prevalece um conjunto de procedimentos informalmente instituídos, pautados por parâmetros distintos daqueles prescritos na formalidade" (Sapori, 2007, p. 59).

Constata-se, assim, que os padrões institucionais e a cultura burocrática que moldaram as práticas policiais no Brasil são muito anteriores e em grande medida ainda comprometem a implantação de um modelo profissional de polícia. Poncioni (2003, p. 72) define o modelo profissional da polícia como um quadro de referência analítico por meio do qual um conjunto de argumentos sobre papel, funções, filosofia de trabalho, administração, estratégias e táticas operacionais - portanto, uma ideia de missão - se organiza para moldar o comportamento policial, em resposta a um mandato da sociedade e na construção de sua legitimidade social. Já para Bonelli (2002, p. 16-19), o profissionalismo pode ser reconhecido a partir da especialização do trabalho, de jurisdição exclusiva dos praticantes sobre a atividade, da posição protegida no mercado de trabalho por credenciais específicas, do programa formal de treinamento e de um ideal de serviço que valorize a realização pelo trabalho e não do ganho financeiro dele advindo. 
No entanto, como lembra Batitucci (2011), se de um lado ainda não consolidamos no Brasil o modelo profissional-burocrático de polícia, os últimos 40 anos testemunharam o desenvolvimento de novas soluções organizacionais para a confrontação das limitações do modelo profissionalburocrático de policiamento, especialmente aquelas voltadas à descentralização do comando nas organizações policiais e à reconsideração da comunidade como um interlocutor qualificado na busca da construção de uma nova relação com a polícia. Uma proposta, portanto, que demandaria uma formação mais generalista e humanista do policial, a descentralização organizacional na administração e, especialmente, a valorização do conhecimento e da experiência do próprio policial, independentemente de sua posição hierárquica

\section{Reforma das polícias: a experiência do Rio de Janeiro}

Desde 1995, o Rio de Janeiro vem buscando modelos alternativos de atuação policial que aproximem os policiais militares das comunidades pobres, conhecidas mais comumente como favelas. A primeira proposta foi a implantação dos Postos de Policiamento Comunitário (PPCs), pautando-se no modelo norte-americano de polícia comunitária. O modelo trouxe alguns elementos novos para o debate, já que os policiais puderam se deparar com a realidade de locais onde os serviços públicos em geral não chegam. Além de ter que lidar com a questão do tráfico de drogas, muito comum nesses contextos, os policiais também tiveram que desempenhar um papel assistencial para o qual não estavam preparados.

A iniciativa não teve continuidade, e no ano 2000 retomou-se a tentativa de policiar as favelas através dos Grupos de Policiamento em Áreas Especiais. Mais uma vez foram destinadas verbas para construção de postos de policiamento, treinou-se policiais em mediação de conflitos e policiamento comunitário, mas essa proposta não vingou. Os grupamentos de policiamento não foram construídos nos moldes apropriados, alguns funcionavam de maneira improvisada em barracões de obra abandonados e não houve adesão por parte dos policiais a essa proposta de policiamento. Na verdade, devido ao "ethos guerreiro" tão evidente na polícia militar, muitos policiais enxergam, ainda hoje, o policiamento comunitário como uma modalidade de policiamento inferior, não combativa, onde atuam como "babás de favelados".

Finalmente, em 2008 foram criadas as Unidades de Polícia Pacificadora (UPPs). De fato, elas trouxeram algumas novidades em relação às propostas anteriores. A primeira delas é que a chegada da UPP foi precedida por operações militares de combate ao tráfico amplamente noticiadas pelas emissoras de TV. A outra novidade é que as UPPs viriam acompanhadas de outros serviços do 
estado que não apenas a força policial. Dessa forma, foram lançados editais convocando especialistas em diversas áreas para atuar na assistência social, educacional, esportiva, urbanizadora e de saúde nesses locais. Porém, essas mudanças não se concretizaram.

Na maioria dos casos esse apoio até hoje não chegou, e são os policiais que vão dia a dia criando mecanismos para atender as necessidades da população. E essa relação nem sempre é harmoniosa, pelo contrário, em alguns casos ela é marcada pelo conflito entre polícia e moradores e pelo arbítrio dos policiais. O caso Amarildo tornou-se exemplar dos abusos cometidos por policiais nesses locais. Por outro lado, os dados criminais divulgados pelo Instituto de Segurança Pública do Rio de Janeiro (ISP), indicam que houve queda de crimes graves como homicídios nos locais que hoje possuem UPPs. Resta esperar os resultados dos estudos que estão em andamento na tentativa de verificar quais os impactos negativos e positivos desse modelo de policiamento que está em vigor no Rio de Janeiro, tentando identificar se de fato a proposta trouxe novidades ou apenas reproduziu as tentativas anteriores de policiamento comunitário com uma nova roupagem. ${ }^{2}$

As tentativas de mudança na atuação policial no Rio de Janeiro, também se debruçaram sobre a polícia civil. O Programa Delegacia Legal (PDL) foi implantado em 1999, através da criação de um grupo executivo composto por policiais e especialistas, com o propósito de qualificar o atendimento ao cidadão. Para isso modificou-se tanto a estrutura funcional quanto a estrutura física das delegacias. Até esse período era comum as delegacias terem carceragens, onde pessoas detidas ficavam muitas vezes por longos períodos, de forma irregular, aguardando sua transferência para uma casa de custódia. Esse procedimento é ilegal, daí o trocadilho com o nome das delegacias, que nesse modelo passaram a se chamar delegacias legais, pois estavam de fato agindo de forma legal, já que agora os detidos permaneciam no máximo 24 horas na delegacia. Como parte da reforma, foram construídas novas delegacias, e outras passaram por reformas, tornando-se assim ambientes mais acessíveis, oferecendo banheiros, bebedouros e telefones públicos. Também foram contratados universitários das áreas de psicologia, serviço social e outros cursos, que ficaram responsáveis por fazer o atendimento inicial dos usuários das delegacias. $\mathrm{O}$ ambiente passou a contar com serviços terceirizados de limpeza e de informática, liberando o tempo dos policiais para as atividades de investigação.

2 Já estão disponíveis importantes trabalhos de investigação sobre o contexto das UPPs no Rio de Janeiro. Entre eles, destacam-se: Fórum Brasileiro de Segurança Pública (2012), Musumeci et al., (2013), Oliveira (2012). 
Além disso, o grupo executivo criou ferramentas de controle, com o intuito de se certificar de que os policiais estavam de plantão na delegacia e não haviam abandonado seu posto para exercer outras atividades, como era comum acontecer.

Todavia, alguns problemas permaneceram. O primeiro deles se refere a certos aspectos relacionados à cultura policial que não foram afetados pelas mudanças. É prática comum na polícia civil que os policiais selecionem que crimes devem ou não ser registrados. Situações envolvendo brigas de vizinho, conflitos domésticos, e outros delitos que são considerados 'menores', nem sempre são registrados. Especificamente no caso de delitos previstos pela Lei de Drogas (lei 11.243/2006), jovens apreendidos portando drogas podem ser tratados de forma diferenciada. Os que possuem nível de instrução e status social mais elevado tendem a ser tratados como usuários e os de classe mais baixa tendem a ser enquadrados como traficantes. Estas práticas não foram alteradas pelos procedimentos adotados nas delegacias legais (Nascimento, 2008).

A questão do controle dos policiais de plantão também não foi tão eficiente quanto o previsto. Era muito comum os policias darem a senha para algum colega que acessava o sistema e fazia o registro no nome do policial ausente, fazendo parecer que ele estava na delegacia. Também se verificou a prática de policiais que assinavam documentos no lugar do delegado, imitando sua assinatura e utilizando seu carimbo, quando o delegado não estava presente, prática identificada como "baixar o santo", em analogia a certas religiões onde o médium incorpora entidades espirituais.

O programa contou com aprovação da população, que enxerga nessas novas delegacias um ambiente mais aprazível que os das delegacias tradicionais, sujas, escuras e desorganizadas. No entanto, um olhar mais cuidadoso sobre essas mudanças aponta que vários aspectos do modelo convencional de delegacias não foi modificado e que não houve um incremento na resolução de crimes.

Utilizamos as polícias do Rio de Janeiro como caso para ilustrar situações que se repetem em todo o Brasil, conforme tem demonstrado diversos pesquisadores que se debruçam sobre o tema desde a década de 80 do século passado. ${ }^{3}$

\footnotetext{
${ }^{3}$ Importante referir aqui o trabalho pioneiro de Mingardi (1992); assim como o estudo de Lima (1991). Mais recentemente, destaca-se o estudo coordenado por Misse (2010).
} 


\section{A PEC 51 e o relatório da Comissão da Verdade: propostas de reforma institucional e obstáculos corporativos}

O desafio de reforma das polícias no Brasil não é simples, pois as barreiras para a mudança são de diversos âmbitos, desde a história institucional, passando pela matriz autoritária e sua atualização no período militar, a estrutura marcada pela divisão do ciclo de policiamento e pelas divisões internas das polícias, o corporativismo e as disputas de poder em torno das funções policiais, a cultura de baixa eficiência na gestão pública e de descontinuidade administrativa, o senso comum punitivista e a pouca propensão do sistema político para atuar de forma contundente para o aperfeiçoamento das instituições policiais (Azevedo, 2016).

O problema da relação entre as polícias civil e militar é bastante conhecido, e remete ao debate sobre a estrutura das polícias no Brasil. No modelo adotado pela Constituição de 1988, há uma divisão do ciclo policial, sendo uma polícia militarizada a responsável pelo policiamento ostensivo, e outra, judiciária, encarregada da investigação criminal. Críticas ao caráter militarizado das polícias militares e à divisão do ciclo de policiamento são conhecidas (Azevedo, 2016).

Há um descontentamento generalizado com relação à estrutura policial vigente, pelos problemas de relacionamento entre as instituições, duplicação de gastos e estruturas, incompatibilidade com o desenvolvimento de uma polícia moderna, etc. Definir os contornos de uma nova polícia, a serviço do esclarecimento dos fatos e da garantia dos direitos fundamentais, exigiria a adoção de uma estrutura e formação policial que rompam com uma cultura institucional construída em meio à precariedade e ao descontrole, reestruturando as relações institucionais entre as polícias e destas com o ministério público e o poder judiciário, e redefinindo as atribuições de cada um destes órgãos no sentido do aperfeiçoamento dos mecanismos de apuração e processamento dos eventos criminais e de controle da atividade policial.

Apresentada ao congresso em 2013, de autoria do senador Lindembergh Farias, a Proposta de Emenda Constitucional (PEC) 51, é a mais ampla tentativa de reforma das instituições policiais, e prevê uma série de mudanças na organização do sistema de segurança pública, entre as quais se destacam as seguintes:

- Carreira única: a partir da fusão das polícias militar e civil, haveria apenas um tipo de carreira policial no país. A hierarquia ainda existiria, mas contaria com menos postos; 
- Ciclo completo: todo órgão policial deverá realizar o ciclo completo de policiamento, o que inclui o policiamento ostensivo, preventivo e investigativo;

- Desvinculação das forças armadas: treinamento policial deixaria de ter caráter militar e passaria a ter caráter civil, com ensino mais voltado ao policiamento comunitário;

- Controle: polícia passaria a contar com ouvidoria externa com orçamento próprio;

- Autonomia: entes federativos ganhariam autonomia para definir o modelo de suas polícias. Cidades com mais de 1 milhão de habitantes poderiam ser responsáveis pela força policial local, desde que os estados assim definissem;

- Conversão: guarda municipal poderia virar polícia municipal;

- Responsabilização: julgamento de policiais militares, nos estados que ainda tem tribunal próprio, passaria a ser civil.

Em linhas gerais, a PEC 51 propõe a flexibilidade para que cada estado defina como irá gerenciar suas estruturas policiais, podendo fundir as duas polícias, mantê-las com ciclo completo ou ainda investir na municipalização do policiamento. Em qualquer caso, ciclo completo, carreira única em cada polícia e estabelecimento de mecanismos de controle são obrigatórios. Estados, municípios e a União teriam seis anos para implantar as mudanças a partir da aprovação da PEC.

Conforme sustentam seus proponentes na exposição de motivos da proposta,

Acreditamos oferecer uma solução de profunda reestruturação de nosso sistema de segurança pública, para a transformação radical de nossas polícias. A partir da desmilitarização da Polícia Militar e da repactuação das responsabilidades federativas na área, bem como da garantia do ciclo policial completo e da exigência de carreira única por instituição policial, pretende-se criar as condições para que a provisão da segurança pública se dê de forma mais humanizada e mais isonômica em relação a todos os cidadãos, rompendo, assim, com o quadro dramático da segurança pública no País (PEC 51/2013).

Para seu principal formulador, Luiz Eduardo Soares, é indiscutível que cumprem papel determinante a militarização e a ruptura do ciclo do trabalho policial para o quadro de violência e superlotação carcerária. Para Soares, A divisão do ciclo, no contexto da cultura corporativa belicista - herdada 
da ditadura e do autoritarismo onipresente na história brasileira -, cria uma polícia exclusivamente ostensiva, cuja natureza militar inibe o pensamento na ponta, cria obstáculo a valorização do policial e de sua autonomia profissional, e mutila a responsabilidade do agente, degradando a discricionariedade hermenêutica em arbitrariedade subjetiva (Soares, 2003).

No relatório final dos trabalhos da Comissão Nacional da Verdade (2015), criada para esclarecer os crimes praticados pelo estado brasileiro durante a ditadura militar e encaminhar propostas para o aperfeiçoamento democrático institucional, das 29 recomendações do documento, 8 delas são diretamente relacionadas à segurança pública: a desmilitarização da polícia militar; a reforma curricular nas academias de polícia; o fim dos autos de resistência; a desvinculação do Instituto Médico Legal (IML) das secretarias de segurança pública e da estrutura policial; a ampliação da defensoria pública; a extinção da justiça militar estadual; a exclusão de civis da jurisdição da justiça militar federal; o fim da lei de Segurança Nacional, de 1983.

Para a Comissão, a militarização da polícia é uma "anomalia" no exercício da segurança pública em uma democracia. Segundo o texto, na estrutura militar, o policial é treinado para combater um inimigo, em vez de atender ao cidadão. Caso concretizada, a recomendação implicaria em uma reconfiguração da estrutura básica da segurança brasileira, começando pela união entre as polícias (militar e civil).

O relatório da Comissão da Verdade ${ }^{4}$ defende ainda a revisão curricular das academias de polícia para garantir mais espaço à promoção da democracia e dos direitos humanos. $\mathrm{O}$ investimento em uma melhor formação policial e a desmilitarização da instituição é tido como a principal forma de reduzir o número de homicídios cometidos por policiais. Apenas entre 2009 e 2013, as forças policiais brasileiras mataram 11.197 suspeitos, o que equivale a seis indivíduos por dia. O número supera as mortes causadas polícia dos Estados Unidos ao longo de 30 anos (11.090).

O relatório da Comissão da Verdade também recomenda a substituição do termo "auto de resistência" nos inquéritos de ações policiais que resultaram em morte ou lesão corporal dos suspeitos. Na avaliação de especialistas, o instrumento muitas vezes é usado para encobrir execuções extrajudiciais e evitar uma investigação criteriosa de homicídios causados por policiais. $\mathrm{O}$ relatório final da Comissão da Verdade recomenda que "as lesões e mortes decorrentes de operações policiais ou de confronto com a polícia sejam registradas como 'lesão corporal decorrente de intervenção policial' e

\footnotetext{
${ }^{4}$ Disponível em: <www.cnv.gov.br/images/pdf/relatorio/volume_1_digital.pdf>.
} 
'morte decorrente de intervenção policial', substituindo os termos 'autos de resistência' e 'resistência seguida de morte', respectivamente".

Em tramitação na Câmara, o projeto de lei 4471, de 2012, prevê que as mortes causadas por agentes do estado tenham um rito de investigação semelhante ao previsto para os crimes praticados por cidadãos comuns. $\mathrm{O}$ objetivo é justamente acabar com os autos de resistência e evitar que os casos sejam arquivados com base em simples justificativas de que os suspeitos resistiram à prisão.

Uma resolução conjunta do Conselho Superior de Polícia, órgão da polícia federal, e do Conselho Nacional dos Chefes da Polícia Civil, publicada no dia 4 de janeiro de 2016 no Diário Oficial da União, aboliu o uso dos termos "auto de resistência" e "resistência seguida de morte" nos boletins de ocorrência e inquéritos policiais em todo o território nacional. A medida, aprovada em 13 de outubro de 2015, mas com vigência somente a partir da publicação no DOU, promove a uniformização dos procedimentos internos das polícias judiciárias federal e civis dos estados nos casos de lesão corporal ou morte decorrentes de resistência a ações policiais. De acordo com a norma, um inquérito policial com tramitação prioritária deverá ser aberto sempre que o uso da força por um agente de estado resultar em lesão corporal ou morte. O processo deve ser enviado ao ministério público independentemente de outros procedimentos correcionais internos das polícias.

Caberá ao delegado responsável pelo caso avaliar se os agentes envolvidos "se valeram, moderadamente, dos meios necessários e disponíveis para defender-se ou para vencer a resistência". O texto determina que, a partir de agora, todas as ocorrências do tipo sejam registradas como "lesão corporal decorrente de oposição à intervenção policial" ou "homicídio decorrente de oposição à ação policial'. Nos casos de morte violenta, passa a ser obrigatório o exame de corpo de delito interno. O laudo deverá ser entregue à autoridade requisitante e à família da vítima em até dez dias. O projeto torna ainda obrigatória a documentação fotográfica dos cadáveres "na posição em que forem encontrados".

Para assegurar que execuções e procedimentos de tortura cometidos por policiais não sejam encobertos pelo estado, a Comissão da Verdade também recomendou que órgãos forenses e de perícia criminal sejam independentes e desvinculados das secretarias de segurança pública e da estrutura policial. Hoje, órgãos como o Instituto Médico Legal (IML) e o Instituto de Criminalística (IC) estão em muitos estados sob a coordenação da polícia civil. Com a independência e autonomia destes institutos de perícia seria possível "con- 
ferir maior qualidade na produção de provas técnicas, inclusive no diagnóstico de tortura", afirma o relatório da Comissão.

Por fim, a implantação do ciclo completo de polícia no Brasil exigiria alteração da Constituição Federal, especificamente do artigo 144, parágrafos 4 e 5. Na nomenclatura jurídica, patrulhamento ostensivo e investigação criminal são concebidos, respectivamente, como polícia ostensiva e preservação da ordem pública, a cargo das polícias militares, e as funções de polícia judiciária e apuração das infrações penais, a cargo das polícias civis. Para se instituir o ciclo completo a Constituição deve afirmar que as duas funções podem ser exercidas pela mesma organização policial.

Considerando a opção pela manutenção do modelo de polícias estadualizadas, Sapori (2016) identifica três opções de implantação do ciclo completo. A primeira opção seria a unificação das polícias civil e militar em cada unidade da federação, criando-se uma única polícia estadual. Teríamos então 27 polícias estaduais no Brasil, e não mais as 54 existentes no modelo vigente. E cada polícia estadual estaria incumbida das funções de policiamento ostensivo, preservação da ordem pública e de polícia judiciária nos limites territoriais do respectivo estado. Haveria, portanto, apenas um comandante/ chefe dessa nova instituição. Cada estado teria que estruturar essa nova polícia, estabelecendo nova estrutura hierárquica, novo regulamento disciplinar, novo plano de carreiras, nova academia de formação e treinamento, etc. Esta opção de ciclo completo de polícia teria como principal vantagem a otimização de recursos humanos e materiais. Os governos estaduais poderiam racionalizar os gastos com o sistema policial, especialmente com imóveis e viaturas, evitando o desperdício com estruturas replicadas, como ocorre no modelo atual com divisão do ciclo. A principal dificuldade deriva do fato de que a dualidade entre policiais militares e civis é muito forte, carregando culturas organizacionais distintas. Esse resquício pode ser transferido para a nova polícia, dificultando a institucionalização da nova identidade organizacional.

Em outra opção, a Constituição Federal estabeleceria que as polícias civis e as polícias militares dos estados teriam, ambas, as funções de polícia ostensiva e de polícia judiciária. Tanto a polícia militar quanto a polícia civil passariam a ter o segmento fardado, responsável pelo patrulhamento ostensivo, e o segmento investigativo, responsável pela condução dos inquéritos policiais. Não seria necessário, apesar de possível, estabelecer procedimentos de transferência de policiais de uma polícia para a outra. Cada estado teria a tarefa de realizar concursos públicos para completar os quadros das novas carreiras a serem criadas em cada uma das polícias. Investimentos adicionais na aquisição de imóveis e equipamentos também seriam inevitáveis. O principal problema 
dessa opção de ciclo completo diz respeito à distribuição de competência territorial. Não seria mais conveniente que as duas polícias continuem atuando nas mesmas cidades. Isso porque não haveria mais complementariedade de trabalho entre elas. Como ambas fariam o ostensivo e o investigativo, atuando em todo e qualquer tipo de crime, a permanência delas na mesma cidade implicaria em sobreposição de atribuições. A competição conflituosa entre as polícias tenderia a ser muito mais intensa do que já o é no modelo atual.

Na terceira opção de ciclo completo apontada por Sapori (2016), seriam atribuídas as funções ostensiva e investigativa tanto às polícias militares quanto às polícias civis, mantendo-as, contudo, na mesma cidade. $\mathrm{O}$ ciclo completo seria dividido por competência penal. Cada polícia ficaria responsável por parte dos crimes e contravenções estabelecidas pelo Código Penal. Teríamos, assim, os crimes e contravenções de competência da polícia militar e os crimes e contravenções de competência da polícia civil. Esse modelo não considera o ciclo completo para ambas as polícias. Na verdade, o que ele contempla é o ciclo completo apenas para a polícia militar, que assumiria prerrogativas na condução de TCOs bem como de inquéritos referentes a crimes de menor gravidade. À polícia civil restaria se concentrar na investigação dos crimes de maior repercussão pública. E o patrulhamento ostensivo continuaria como prerrogativa da polícia militar.

\section{Considerações finais}

Para concluir, é importante referir o papel que tem desempenhado o Fórum Brasileiro de Segurança Pública na consolidação do debate público sobre o tema e na aproximação de diferentes atores relacionados com o campo da segurança pública no Brasil. Criado em 25 de fevereiro de 2006 por pesquisadores, policiais e gestores públicos, o Fórum surgiu com o propósito de reunir e colocar em diálogo atores chave para a consolidação democrática na área da segurança pública. Por isso mesmo, a proposta da entidade sempre foi a de garantir a pluralidade de ideias e de perspectivas em torno dos desafios para a redução da criminalidade e o aperfeiçoamento das instituições responsáveis pela segurança pública, a partir de uma carta de princípios $^{5}$ que reafirma a democracia como compromisso maior em torno do qual as propostas e iniciativas da entidade devem estar articuladas.

A transparência na produção e análise de dados sobre a criminalidade, a letalidade e a vitimização policial, a elucidação dos efeitos do encarceramento,

\footnotetext{
${ }^{5}$ Disponível em: <www.forumseguranca.org.br/files/files/Carta_de_principios_-_FBSP.pdf $>$.
} 
e a ampliação do controle público sobre a atividade policial, identificando e disseminando boas práticas, têm sido os eixos estratégicos em torno dos quais tem se articulado as iniciativas da entidade, assim como de um conjunto de outros atores da sociedade civil, que tem buscado aproximar diferentes segmentos e construir pontes de diálogo e produzir uma nova agenda para o setor.

É a partir de análises e pesquisas desenvolvidas por pesquisadores ligados ao Fórum que se pode identificar os elementos aqui apontados para as dificuldades enfrentadas para a reforma das instituições de segurança pública no Brasil: falta de continuidade dos programas e políticas, cultura policial ainda refratária aos mecanismos de controle e à transparência, estrutura defasada, que divide o ciclo de policiamento em duas metades, cada uma a cargo de uma polícia, cujas carreiras são também divididas, e a não constituição de um sistema nacional de segurança pública que integre as iniciativas da União, estados e municípios

Vale referir, ainda, no âmbito discursivo, a permanência de uma dicotomia que coloca em confronto o "discurso simplório" e o "discurso crítico", e que pouco contribui para as necessárias mudanças. O discurso simplório ou de senso comum é apresentado cotidianamente por diversos atores do campo político e da segurança, que diante do fracasso dos sucessivos governos em reduzir a violência culpam uma genérica flacidez legislativa, fruto da força dos defensores dos direitos humanos no pós-ditadura, que teriam enfraquecido a ação do estado e inviabilizado o combate ao crime, por imporem às polícias uma atuação em padrões constitucionais e ao sistema penal a garantia do direito de defesa e a proteção da dignidade humana na execução da pena. Pouco interessa aos formuladores deste discurso (por isso mesmo simplório) que a realidade o desminta cotidianamente, uma vez que os padrões de funcionamento democrático do sistema ainda não foram assegurados, e o desrespeito aos direitos ainda é a regra para amplos setores da população.

De outro lado, o "discurso crítico", com presença marcante em determinados grupos de diletantismo acadêmico, acusa o estado de instituir uma "sociedade do controle", inibindo os direitos individuais e impondo regras e procedimentos incompatíveis com a liberdade e a privacidade, e ataca as polícias como as exclusivas responsáveis pela exacerbação da violência. As altíssimas taxas de violência seriam apenas o subproduto de uma sociedade desigual e excludente, e não haveria motivos para buscar alterar os padrões de atuação das instituições estatais responsáveis pelo controle do crime, predestinadas a agirem indefinidamente como puramente repressivas e violentas contra os setores sociais discriminados e vulneráveis. 
O medo e a insegurança configuram a experiência social contemporânea, esvaziando o espaço público, reduzindo a confiança na democracia e nas instituições e arregimentando novos adeptos às facções criminais (dentro e fora da estrutura estatal) e à caixa de pandora dos discursos de lei e ordem. Desde 1988, com a promulgação da atual Constituição Federal, o Brasil passou a trilhar um novo caminho de afirmação democrática. Mesmo sujeitos às críticas de setores conservadores, dentro e fora das polícias, que passaram a se considerar de "mãos amarradas" para atuar contra o crime, e de setores "críticos", que consideravam a aposta no estado democrático de direito uma impossibilidade no contexto brasileiro, produziu-se um novo consenso entre atores chave sobre a ação do estado no controle do crime, com respeito à lei e a padrões profissionais de enfrentamento de conflitos. Muito ainda ficou por ser feito, como a reforma das estruturas policiais, com a adoção do ciclo completo de policiamento e da carreira única de polícia, e a consolidação de padrões profissionais de atuação por meio da formação e da valorização dos bons profissionais. Levar adiante esta agenda de reformas talvez seja o pressuposto necessário para que não ocorra o retrocesso, com a consolidação da opção pelo populismo punitivo e a reafirmação de um padrão inquisitivo, violento e arbitrário de funcionamento contra os que se colocam sob os holofotes do controle policial e judicial penal.

Para não me alongar, fico, neste sentido, com a opinião do amigo Luiz Eduardo Soares, que há pouco tempo publicou um artigo no blog da Boitempo Editorial, <http://blogdaboitempo.com.br/2015/07/13/por-que-tem-sido-taodificil-mudar-as-policias/>, em que analisa as dificuldades para mudar a segurança pública no Brasil. Alíás, o Luiz estará novamente palestrando em Porto Alegre sobre o tema na próxima segunda-feira, às 9h, no auditório do prédio 11 da PUC. Aqui um trecho em que ele apresenta as concepções teóricas e ideológicas que dificultam a mudança: "Entre os motivos desta indisposição para assumir uma agenda de mudanças para a segurança - que começou a ser revista nas jornadas de junho de 2013 -, incluo algumas concepções teóricas e ideológicas:

a) É preciso uma agenda de transformações das estruturas sociais, não da segurança pública, uma vez que esta última seria apenas uma consequência, um reflexo ou "epifenômeno" das relações sociais de dominação de classe. Inspirando-se na obra de Lenin, "O Estado e a revolução", quem pensa nesses termos acredita que o Estado funcione como engrenagem uniforme a serviço da opressão capitalista. Por isso, não haveria nada a fazer, enquanto a revolução não substituísse o capitalismo por uma ditadura de classe alternativa. Qualquer esforço 
no sentido de promover reformas estaria fadado ao fracasso ou, pior, apenas difundiria ilusões, retardando a tomada de consciência quanto à inelutabilidade da revolução. E ainda por cima talvez acabasse cúmplice da dominação social, aperfeiçoando seus instrumentos repressivos e ampliando a faixa de sua aceitabilidade. Portanto, diante de cada crise da segurança que afete os mais pobres, a postura de seus pretensos porta-vozes revolucionários tende a ser: o que está em curso não é mau policiamento, mas bom policiamento para o sistema, porque tudo o que acontece, inclusive no campo da segurança, dá-se como realização de interesses e vontades políticas de classe, ou em seu benefício. O Estado não é espaço de contradições e disputas, tampouco existem efeitos perversos ou efeitos de agregação das ações sociais, assim como as linhas de ação dos setores dominantes nunca erram quanto a seus próprios interesses, e as iniciativas cuja fonte seja o Estado funcionam, isto é, encaixam-se nesse organismo funcional do poder, nessa mônada opaca e impermeável.

b) Ainda que a sociedade e o Estado sejam porosos, sujeitos de e a contradições as mais diversas, atravessados por mediações complexas, e ainda que os atores nunca sejam oniscientes e que o emaranhado das ações esteja longe de espelhar desejos e planos, interesses e projetos, econômicos e políticos, ainda assim nada do que ocorre na esfera da segurança pública é indiferente à autorização da sociedade. Por conseguinte, antes de qualquer providência reformista voltada especificamente para organizações e comportamentos dos agentes da segurança e da justiça criminal, seria necessário mudar as visões hegemônicas sobre guerra, inimigos internos e a descartabilidade dos vulneráveis. Se as polícias agem de modo francamente racista e adotam nítido viés de classe, se territórios são estigmatizados, os problemas não estão nessas instituições e em seus profissionais, mas na sociedade, em sua história. Sem que a cultura anti-democrática seja transformada, seria equivocado e fantasioso tentar mudar as corporações policiais, suas táticas, métodos, abordagens e comportamentos.

c) Independentemente das convicções sobre economia, política e sociedade, o que importa é denunciar os abusos policiais, não oferecer alternativas. Todo poder deve ser confrontado e nada mais representativo do caráter odioso deste pan-poder estatal do que a polícia, quaisquer que sejam suas formas e seus comportamentos. Nem "democracia burguesa", nem "ditadura do proletariado": 
regimes políticos e modos de produção são indiferentes. Reduzem-se a variações em torno do mesmo mote e destino: o poder e a disciplina, dos saberes aos corpos. Assim como democracias não se distinguem de ditaduras, polícia é sempre polícia: um mal a exorcizar.

(d) Vale a pena lutar por transformações tópicas na esfera da segurança pública e de suas instituições, porque as ações destas últimas afetam os grupos sociais mais pobres e estigmatizados, incidem sobre as condições de vida nos territórios mais vulneráveis e influenciam a participação cidadã, obstruindo-a ou a facilitando. Entretanto, segurança não deve ser tomada como um bem universal, porque forças progressitas não deveriam envolver-se na proteção da propriedade, numa sociedade tão desigual quanto a nossa, nem deveria tomar como um problema o crime perpetrado por atores sociais vítimas da sociedade de classes. Enfim, controlar a violência policial constitui um objetivo importante e alcançável, porque formatos distintos e culturas corporativas diferentes produzem, sim, efeitos distintos e até opostos. Todavia, propor políticas de segurança para reduzir os mais diversos tipos de crime não seria tarefa de um ativista de esquerda. Por isso, corrupção seria um tema perigoso, suscitando tantas ambiguidades: bom para acusar adversários políticos, quando se está na oposição; ruim para engendrar um discurso republicano de natureza universalista, uma vez que, segundo este quarto ponto de vista (e, provavelmente, também os anteriores), a corrupção seria traço intrínseco ao sistema.

\section{Referências}

AZEVEDO, Rodrigo Ghiringhelli. Elementos para a modernização das polícias no Brasil. Revista Brasileira de Segurança Pública, v. 10, p. 8-20, 2016.

AZEVEDO, Rodrigo Ghiringhelli; CIFALI, Ana Cláudia. Seguridad pública, política criminal y penalidad en Brasil durante los gobiernos Lula y Dilma (2003-2014) Cambios y continuidades. In: Maximo Sozzo (org.). Postneoliberalismo y penalidad en América del Sur. Argentina: Clacso, 2016. p. 29-94.

AZEVEDO, Rodrigo G. (org.). As políticas públicas de segurança no âmbito municipal: uma análise comparada das cidades de Canoas, RS e Jaboatão dos Guararapes, PE. Senasp, Pensando a segurança pública, v. 3, 2012. p. 283-375 <justica.gov.br/suaseguranca/seguranca-publica/analise-e-pesquisa/download/estudos/pspvolume3/4-aspoliticas-de-seguranca-no-ambito-municipal-3.pdf $>$.

BATITUCCI, Eduardo Cerqueira. A polícia em transição: o modelo profissionalburocrático de policiamento e hipóteses sobre os limites da profissionalização das polícias brasileiras. Dilemas: Revista de Estudos de Conflito e Controle Social, v. 4, n. 1, p. 65-96, 2011. 
BONELLI, Maria da Glória. Profissionalismo e politica no mundo do direito. São Carlos: EdUFScar. 2002.

BRASIL. Presidência da República. Secretaria Geral. Mapa do encarceramento: os jovens do Brasil. Brasília: Presidência da República, 2015.

CARUSO, Haydée Glória Cruz. Das práticas e dos seus saberes: a construção do "fazer policial" entre as praças da PMERJ. Niterói, 2004. Dissertação de Mestrado, Programa de Pós-graduação em Antropologia, Universidade Federal Fluminense.

COMISSÃO Nacional da Verdade. Relatório final. 2015. <http://www.cnv.gov.br/> (30 mar. 2016).

FÓRUM Brasileiro de Segurança Pública. A segurança pública em números. Anuário Brasileiro de Segurança Pública, v. 9, p. 11-19, 2015 <www.forumseguranca.org.br/ storage/download//anuario_2015.retificado_.pdf> (4 dez. 2016).

FÓRUM Brasileiro de Segurança Pública. Os donos do morro: uma análise exploratória do impacto das Unidades de Polícia Pacificadora no Rio de Janeiro, 2012. Relatório de Pesquisa <www.forumseguranca.org.br/storage/download/os_donos_do_morro.pdf $>$.

HOLLOWAY. Thomas. Polícia no Rio de Janeiro: repressão e resistência numa cidade do século XIX. Rio de Janeiro: Fundação Getúlio Vargas, 1997.

LIMA, Roberto Kant de. A polícia na cidade do Rio de Janeiro. Rio de Janeiro: Ed. Forense, 1991.

LIMA, Roberto Kant de. Entre as leis e as normas: éticas corporativas e práticas profissionais na segurança pública e na Justiça Criminal. Dilemas: Revista de Estudos de Conflito e Controle Social, v. 6, n. 3, p. 549-580, 2013.

LIMA, Roberto Kant de. Éticas e práticas na segurança pública e na justiça criminal. In: Renato Sergio de Lima; José Luiz Ratton; Rodrigo Ghiringhelli de Azevedo (orgs.). Crime, polícia e justiça no Brasil. São Paulo: Contexto, 2014. p. 471-481.

MINGARDI, Guaracy. Tiras, gansos e trutas: cotidiano e reforma na polícia civil. São Paulo: Scritta, 1992.

MISSE, Michel. O inquérito policial no Rio de Janeiro: mudanças recentes, alcances, tradições e especificações. In: Michel Misse (org.). O inquérito policial no Brasil: uma pesquisa empírica. Rio de Janeiro: Booklink, 2010. p. 23-101.

MUSUMECI, Leonarda; MOURÃO, Barbara Musumeci; LEMGRUBER, Julita; RAMOS, Silvia. Ser policial de UPP: aproximações e resistência. Boletim Segurança e Cidadania, v. 14, 2013.

NASCIMENTO, Andrea Ana. Entre a tradição e a mudança: reflexões sobre a reforma da polícia civil do estado do Rio de Janeiro. Enfoques, v. 7, n. 1, p. 91-111, 2008.

NASCIMENTO, Andrea Ana. A especialização sem especialistas: um estudo sobre as práticas (in) formais de investigação e de transmissão de conhecimento nas delegacias especializadas. Rio de Janeiro, 2004. Dissertação de Mestrado, Programa de Pósgraduação em Sociologia e Antropologia, Universidade Federal do Rio de Janeiro.

NASCIMENTO, Andrea Ana. Quando um homem de lei torna-se um sem lei: os caminhos da corrupção policial. Tese de Doutorado, PPG em Sociologia, UFRJ, 2014. 
OLIVEIRA, Fabiana Luci de. UPPs, direitos e justiça: um estudo de caso das favelas do Vidigal e do Cantagalo. Rio de Janeiro: Editora FGV, 2012.

PINHEIRO, Paulo Sérgio. Violência, crime e sistemas policiais em países de novas democracias. Tempo Social, v. 9, n. 1, p. 43-52, $1997<10.1590 /$ ts.v9i1.86438>.

PONCIONI, Paula. Identidade profissional policial. In: Renato Sérgio de Lima; José Luiz Ratton; Rodrigo Ghiringhelli de Azevedo (orgs.). Crime, policia e justiça no Brasil. São Paulo: Contexto, 2014. p. 503-510.

PONCIONI, Paula. Tornar-se policial: a construção da identidade profissional do policial do estado do Rio de Janeiro. São Paulo, 2003. Tese de doutorado em Sociologia, Universidade de São Paulo.

SAPORI, Luís Flávio. Segurança pública no Brasil: desafios e perspectivas. Rio de Janeiro: Editora FGV, 2007.

SAPORI, Luís Flávio. Como implantar o ciclo completo de polícia no Brasil? Revista Brasileira de Segurança Pública, v. 10, p. 50-58, 2016.

SENADO Federal. Proposta de Emenda Constitucional n. 51. <https://www25. senado.leg.br/web/atividade/materias/-/materia/114516> (15 mar. 2016).

SOARES, Luiz Eduardo. PEC-51: revolução na arquitetura institucional da segurança pública, 2003. <http://www.luizeduardosoares.com/?p=1185> (30 mar. 2016).

TORELLY, Marcelo Dalmás. Justiça de transição e estado constitucional de direito: perspectiva teórico-comparativa e análise do caso brasileiro. Belo Horizonte: Fórum, 2012.

ZALUAR, Alba. Democratização inacabada: fracasso da segurança pública. Estudos Avançados, v. 21, n. 61, p. 31-49, $2007<10.1590 /$ S0103-40142007000300003>.

Autor correspondente:

Rodrigo Ghiringhelli de Azevedo

Rua Conde da Figueira, 458, casa 3

91330-590 Porto Alegre, RS, Brasil

Recebido em: 27 jun. 2016

Aprovado em: 7 nov. 2016 